\title{
Prevalence and Nature of Medication Errors and Medication-Related Harm Following Discharge from Hospital to Community Settings: A Systematic Review
}

\author{
Fatema A. Alqenae ${ }^{1}\left[\right.$ Douglas Steinke ${ }^{1}\left[\right.$ D $\cdot$ Richard N. Keers $^{1,2}[\mathbb{C}$
}

Published online: 3 March 2020

(c) The Author(s) 2020

\begin{abstract}
Background Little is known about the epidemiology of medication errors and medication-related harm following transition from secondary to primary care. This systematic review aims to identify and critically evaluate the available evidence on the prevalence and nature of medication errors and medication-related harm following hospital discharge.

Methods Studies published between January 1990 and March 2019 were searched across ten electronic databases and the grey literature. No restrictions were applied with publication language or patient population studied. Studies were included if they contained data concerning the rate of medication errors, unintentional medication discrepancies, or adverse drug events. Two authors independently extracted study data.

Results Fifty-four studies were included, most of which were rated as moderate (39/54) or high (7/54) quality. For adult patients, the median rate of medication errors and unintentional medication discrepancies following discharge was 53\% [interquartile range 33-60.5] ( $n=5$ studies) and 50\% [interquartile range 39-76] ( $n=11)$, respectively. Five studies reported adverse drug reaction rates with a median of $27 \%$ [interquartile range 18-40.5] and seven studies reported adverse drug event rates with a median of $19 \%$ [interquartile range 16-24]. For paediatric patients, one study reported a medication error rate of $66.3 \%$ and another an adverse drug event rate of $9 \%$. Almost a quarter of studies $(13 / 54,24 \%)$ utilised a follow-up period post-discharge of 1 month (range 2-180 days). Drug classes most commonly implicated with adverse drug events were antibiotics, antidiabetics, analgesics and cardiovascular drugs.

Conclusions This is the first systematic review to explore the prevalence and nature of medication errors and adverse drug events following hospital discharge. Targets for future work have been identified.
\end{abstract}

Prior publication: This project has been presented as a poster at the Prescribing and Research In Medicines Management (PRIMM) UK and Ireland 30th Annual Scientific Meeting (14 December, 2018, London, UK), “A Systematic Review of Medication Errors and Medication Related Harm Post Hospital Discharge". An abstract of this submission is published in Pharmacoepidemiology and Drug Safety, Volume 28, Issue S1. In addition, this project was presented as a poster at the HSJ Patient Safety Congress in Manchester, UK on 2-3 July, 2019, "How Common are Medication Errors and Medication Related Harm After Hospital Discharge? A Systematic Review”.

Electronic supplementary material The online version of this article (https://doi.org/10.1007/s40264-020-00918-3) contains supplementary material, which is available to authorized users.

Fatema A. Alqenae

Fatema.alqenae@postgrad.manchester.ac.uk

Extended author information available on the last page of the article

\section{Key Points}

Studies found that the median rate of medication error $(n=5)$ or unintentional medication discrepancy $(n=11)$ was nearly $50 \%$ in adult and elderly patients after hospital discharge.

Nearly $20 \%$ of adult and elderly patients in studies $(n=7)$ were reported to be affected by adverse drug events (ADEs) after hospital discharge.

Drug classes most commonly reported with ADEs post-hospital discharge were antibiotics, antidiabetics, analgesics and cardiovascular drugs.

Further research is needed to examine the burden of medication errors, preventable ADEs and ADEs posthospital discharge in all populations, in particular paediatric populations. 


\section{Introduction}

Transitions of care can be defined as "changes in the level, location, or providers of care as patients move within the healthcare system" [1]. Whilst they are intended to be seamless and safe, care transitions are known to place patients at risk of adverse outcomes including medication errors (MEs), missed test results and adverse events including hospital readmission [2].

As healthcare providers may be poorly affiliated across care boundaries, miscommunication during handoff makes the transition of care a fertile ground for MEs and preventable harm [3]. In March 2017, the burden of risk associated with medication safety at the transfer of care was brought to the global attention with the publication of the World Health Organization (WHO) Third Global Patient Safety Challenge: Medication Without Harm, where transitions featured as one of three priorities for action [4].

Medication safety challenges at the point of hospital admission have been well documented $[5,6]$ but these issues may also occur shortly after hospital discharge. The time period immediately following hospital discharge can be a challenging time for patients, both in terms of safety but also socially and emotionally, when patients may be anxious and suffer with functional impairment [7]. This in turn may have an impact on medication adherence, and may increase the risk of adverse drug events (ADEs) (see Sect. 2.2 for the terminology of medication safety terms) [8,9]. Medication regimes are often known to undergo significant changes during hospitalisation, where medications may be stopped, replaced, and undergo changes in doses or frequency and new medications may be initiated [10]. Communication gaps may compound the risk and include delayed/lack of discharge letters, insufficient monitoring plans $[3,11]$ and incomplete or poor-quality discharge summaries [12, 13]. Recent evidence indicates that adverse drug reaction (ADR)related hospital readmissions occur with a median rate of $20 \%$ of patients [interquartile range (IQR) 7-23] $(n=4)$, and ADE-related hospital readmissions with a rate of $13 \%(n=1)$ [14]. Unjustified medication at hospital discharge may not only affect patient safety but may also be associated with a high financial burden [15].

There is an emerging body of literature that reports on the prevalence and nature of MEs and ADEs [16] as well as medication discrepancies [17-19] at the point of hospital discharge (i.e. before patients return home). In contrast, our collective understanding from available studies investigating the burden of MEs and ADEs in the period following hospital discharge to the community is limited, owing in part to there being no up-to-date published systematic reviews on this topic across all patient groups. One previous systematic review of drug-related problems occurring post-hospital discharge in elderly populations was published almost 10 years ago [20] and another from 2018 focused on medication-related harm also in elderly populations [21]. Given the level of interest in this stage of the patient journey amongst health leaders [22] and as new studies emerge in the field [23, 24], there is a need to identify and collectively appraise global evidence on the burden and nature of MEs/ADEs post-hospital discharge across populations to best inform the development of remedial interventions and advance the WHO patient safety agenda. This systematic review therefore aimed to identify and critically appraise the available international evidence on the prevalence and nature of MEs and ADEs following transition of care from hospital to community settings.

\section{Methods}

This systematic review follows the criteria specified in the "Preferred Reporting Items for Systematic Review and MetaAnalysis (PRISMA)", 2015 statement [25]. A PRISMA checklist is included in Appendix 1 of the Electronic Supplementary Material (ESM).

\subsection{Search Strategy}

Ten electronic databases were searched: MEDLINE, EMBASE, International Pharmaceutical Abstracts (IPA), Health Management Information Consortium (HMIC), PsycINFO, Cochrane Database of Systematic Reviews, Cochrane Central Register of Controlled Trials (CENTRAL), Database of Abstracts of Reviews of Effects (DARE), Cumulative Index to Nursing and Allied Health Literature (CINAHL) and Web of Science [26, 27]. A grey literature search was completed using Open Grey via the website http://www.opengrey.eu that is based on the "System for Information on Grey Literature in Europe" (SIGLE) database. The grey literature includes unpublished research (e.g. dissertations or theses), published non-research literature (e.g. government reports or newsletters), studies in progress and recently published studies pending to be referenced in databases [28].

The search was limited to between January 1990 and March 2019. The search strategy was developed using terms related to three categories; epidemiology, process and outcomes. The search included the following keywords and their synonyms: ('rate' OR 'prevalen*') AND ('hospital discharge*' OR 'care transition*') AND ('medication error*' OR 'adverse drug event*'). Search terms underwent minor modification to suit different databases. An example of the search strategy is included in Appendix 2 of the ESM. 


\subsection{Definitions}

Studies that reported events broadly meeting our adapted outcome definitions (see Table 1) were included. Unintentional medication discrepancies (UMDs) were considered MEs but were reported separately. Studies reporting prescribing errors and medication administration errors were considered MEs. Studies evaluating drug-related problems were included if they explicitly reported distinct ME or drug-related harm data and rates were able to be subsequently extracted. Studies evaluating medication adherence were not included as our focus was on iatrogenic complications. The patient populations were considered to be/include the elderly if studies predominantly included patients with chronological age $\geq 60$ years, or if studies said/implied they were studying elderly patients $[29,30]$.

\subsection{Inclusion Criteria}

Quantitative studies that reported a rate of MEs, UMDs, and/or medication-related harm including ADRs and/or ADEs identified during the time period following hospital discharge to community settings (or provided enough data to calculate a rate manually) were sought. Studies were included if data were collected after discharge to community settings including the patients' own home, care/nursing homes, rehabilitation/intermediate care facilities and other long-term care facilities. Interventional studies were only included if they provided baseline data on outcome rates. Grey literature and all original peer-reviewed research except review and editorial articles were included. The reference lists of relevant reviews/editorials were screened for additional studies. Conference abstracts were included only if they provided suitable data regarding ME/UMD or drug-related harm rates (or enough data to calculate these). No restrictions were applied to the age or groups of patient populations included. No language restriction was applied.

\subsection{Exclusion Criteria}

Studies that reported an estimated denominator or those that did not use empirically collected data (data gathered by experimentation or observation) were excluded. Studies restricted to measuring non-adherence, or potentially inappropriate prescribing were excluded. Studies that measured outcomes of interest arising from interviews and questionnaires, or used data from incident reporting systems alone were also ineligible because of reporting and hindsight bias [37]. Studies that reported outcome rates for a specialised ward(s)/ward group(s)/hospital(s) [e.g. oncology, cardiac], a single disease, single drug class, single drug or pre-defined drug class were excluded, as the review intended to produce generalisable findings. Studies that reported outcome rate data limited to events arising from new or altered medication regimes during hospitalisation or at discharge were excluded. Finally, studies were excluded if they predominantly focused on patients discharged home from the emergency department or those with regular planned admissions.

\subsection{Screening Process}

The study screening process was completed by the lead researcher based on the inclusion and exclusion criteria. Initially, duplicate titles were removed followed by the title screening stage and then an abstract screening stage [38]. This was followed by full-text screening along with

Table 1 Definitions

\begin{tabular}{ll}
\hline Term & Definition \\
\hline Adverse drug reactions (ADRs) & "A response to a drug which is noxious and unintended, and which occurs at doses normally \\
& used in man for the prophylaxis, diagnosis, or therapy of disease, or for the modification of \\
physiological function" [31] & "An injury resulting from medical intervention related to drug" [32] \\
Adverse drug events (ADEs) & "Harm caused by the use of a drug as a result of an error" [33] \\
Preventable adverse drug events (pADEs) & "A medication error is any preventable event that may cause or lead to inappropriate medica- \\
Medication errors (MEs) & $\begin{array}{l}\text { tion use or patient harm while the medication is in the control of the health care profes- } \\
\text { sional, patient, or consumer. Such events may be related to professional practice, health care } \\
\text { products, procedures, and systems, including prescribing, order communication, product }\end{array}$ \\
& $\begin{array}{l}\text { labelling, packaging, and nomenclature, compounding, dispensing, distribution, administra- } \\
\text { tion, education, monitoring, and use" [34] }\end{array}$ \\
"Difference between medications taken by a patient prior to admission and medications \\
ordered in the hospital” [35]. Pippins [35] stated that discrepancies are either intentional \\
(not an error, either documented or not) or unintentional (medication error). For our study \\
we included only unintentional medication discrepancies, using an adapted definition by \\
Mueller et al. [36] "unexplained differences in documented medication regimens across \\
different cite of care"
\end{tabular}


the identification of additional studies from the reference lists of included studies and relevant review articles. Titles, abstracts and full texts that were considered unclear for inclusion were discussed with the review team and consensus reached.

Papers published in non-English language had their English abstract screened for inclusion. The abstract mentioning discharge and medication had their full paper translated into English by Google Translate ${ }^{\circledR}$ for inclusion. Google Translate ${ }^{\circledR}$ was found to be around $90 \%$ accurate in a recent study by Jackson et al. [39]. If the study was deemed potentially relevant and considered for a full-text review, a medically trained native speaker would be sought to translate the paper [40]. However, no non-English language papers were found relevant for a full-text review.

\subsection{Data Extraction}

Data extraction for each included study was carried out independently by two reviewers using a standardised tool in Appendix 3 of the ESM. The data extraction tool contents were imported into Microsoft Excel ${ }^{\circledR}, 2010$ (Microsoft, Redmond, WA, USA) for analysis, where each row represented one publication. The reviewers then met to discuss the results and resolve any discrepancies.

Published study authors were contacted for missing or unclear information. Authors of conference abstracts were contacted to determine if a full-text publication was available. Each author was contacted a maximum of three times, over 8 weeks; if no answer was provided, then the paper was excluded [41]. For all screened papers and the cohort of included papers, the author response rate following contact attempts was 55\% (76/139) and 61.5\% (24/39), respectively.

\subsection{Quality Assessment}

Prior to inclusion, exclusion criteria were applied to ensure included studies presented empirically collected data with a suitable denominator [42]. The second stage of quality assessment was completed by the lead researcher using an adapted, validated quality appraisal framework for medication safety studies established by Allan and Barker [43]. The framework used to assess the quality of included studies was originally made to assess ME studies; however, we have adapted the tool to assess the quality of ME and ADE studies. This framework has been successfully applied in other systematic reviews of MEs and ADEs [44-47]. The framework appraises study internal validity by assessing the quality of outcome reporting.

\subsection{Data Synthesis}

Outcome event rates including ME, UMD, ADE and ADR rates were calculated as either the denominator value affected by at least one event (numerator) per total denominator value (e.g. patients affected by at least one ME over total number of included patients), or as the total number of events per total denominator value (e.g. total number of MEs per total number of patients). Denominator values were either discharged patients, doses administered, individual prescribed medications or whole prescriptions. Only studies that provided the outcome rate using the denominator value affected by at least one event (numerator) were used in median (IQR) calculations to avoid inflating outcome rates if more than one event could be counted per denominator value.

The degree of heterogeneity of the included studies meant that a meta-analysis of the data was not possible. Instead, median outcome rates for different medication safety outcome denominators and studies focusing on particular age groups were calculated along with interquartile ranges (IQRs). Comparisons were drawn between studies and basic descriptive statistics provided for the country/ year of origin, method of data collection, definitions of outcome events, severity of outcome events and medication types/classes involved. Medication classes implicated with events were considered 'common' if they were reported at least in four studies as being within the top three most common medications involved in safety events.

\section{Results}

\subsection{Overview of Included Studies}

The total number of citations identified was 22,082. After removing duplicates, this number fell to 16,571 . The PRISMA flow diagram (Fig. 1) illustrates the citation review stages. All included studies are summarised in one table in Appendix 4 of the ESM, followed by tables in Appendixes 5-8 of the ESM, which summarise these studies based on the medication safety measure (ME, ADE, ADR, UMD).

In total, 54 studies were included in the systematic review, including 20,895 hospital discharges across 26 countries. The included studies consisted of 41 published papers [23, 24, 48-86] and 13 conference abstracts [87-99]. One of the included conference abstracts [88] was combined with one letter to the editor [100]. All included studies were published in English.

The majority of included studies were conducted in the United States of America (USA) (17/54, 31.5\%) [52, 54-57, $61,70,74,76,78,79,82,89,90,94,96,97]$, followed by 
the United Kingdom (UK) $(7 / 54,13 \%)[24,49,50,59,87$, $95,98]$. Forty-three $(79.6 \%)$ studies were published from the year 2010 onwards [23, 24, 51-53, 56-61, 64-70, 72, $73,75-82,84,85,87-99]$. Of the 54 studies, 28 (51.8\%) included adult patients, 18 (33.3\%) focused specifically on elderly patients. Three studies $(5.5 \%)$ were exclusively conducted in paediatric patients [75, 86, 95]. Most studies $(85.2 \%, 46 / 54)$ were prospective in design $[23,24,48-52$, $54,55,57-60,63-78,80,81,83,85,86,89-93,95-99]$ ].

Seventy six percent of studies (41/54) included patients who were discharged home $[24,49-54,56-59,61,62,64$, $65,67-72,74-82,85-88,92,94-99]$, with three $(5.5 \%)$ including patients discharged to nursing homes $[60,66$, 98]. The most frequent data collection method was screening case summaries [e.g. discharge medical record and discharge summary] $(43 / 54,79.6 \%)$, followed by telephone follow-up interviews with the patient $(25 / 54,46.2 \%)$. Data collectors were mostly pharmacists $(27 / 54,50 \%)$. Almost a quarter of included studies $(13 / 54,24 \%)$ utilised a followup period post-discharge of 1 month, with the next most common time period being 1 week $(7 / 54,12.9 \%)$. The shortest follow-up period was 2 days and the longest was 180 days. Table 2 summarises key study characteristics.

\subsection{Quality Assessment of Included Studies}

A summary of the quality assessment of included studies is provided in Table 3 . The quality assessment score was low (score $=1-4$ ) in $14.8 \%$ of studies $(8 / 54)$, moderate (score $=5-8)$ in $72.2 \%(39 / 54)$ and high (score $=9-12)$ in $12.9 \%$ (7/54). The aim and objectives were clearly described in all but one paper [96] and the outcome definition was clearly mentioned in 27 papers $[24,49,50,53$, $54,56,58-62,64,68-70,72,75,76,79-86,88]$. In studies that measured drug-related problems (DRPs) but also reported data on MEs/ADEs, reported definitions of DRPs were accepted. The definition of a DRP was provided in six studies $[53,56,58,76,79,81]$ out of the cohort of 27 studies that mentioned outcome definitions. Error categories were mentioned in 14 studies [23, 24, 60, 61, 65, $70-72,75,81,85,87,90,97]$ but were only defined in five studies $[60,72,75,85,87]$. The outcome denominator was clearly defined in all papers and the data collection method was described clearly in all but one study [91]. The study setting was clearly described in all but six studies [73, 80, $90,91,93,98]$. Validity measures, to assess if independent personnel or an expert panel evaluated the event other than the data collector, were applied in 29 studies [23, 24, 48, $50,54-59,61,62,64-67,69,70,72,74,77-80,83,84$, $86,94,95]$ to confirm the occurrence of medication safety outcomes. Reliability measures to evaluate if a formal test/ evaluation (e.g. Kappa test or consensus) was completed to assess inter-rater reliability were applied in 12 studies [24, $50,54,61,65,66,70,74,78-80,83]$. Nearly two thirds of the included papers reported their limitations with 16 papers (including 11 conference abstracts $[49,58,67,68$, 86, 89-99]) not reporting this information. Only nine studies $[24,59,60,63,75,80,81,83,98]$ calculated sample size, with five studies $[60,75,77,83,98]$ describing any assumptions made.

\subsection{Medication Error Studies}

In total, 12 studies $[23,65,71,72,75,85,87,89,90,96,97$, 99] reported data concerning the frequency of MEs. Six studies used established definitions of MEs [23, 71, 72, 75, 85, 87], with one study developing their own definition [90], and five not reporting any definition $[65,89,96,97,99]$. Five studies $[71,72,87,90,97]$ reported data specifically concerning prescribing errors, of which two $[72,87]$ used the prescribing error definition proposed by Dean et al. [101].

All studies explicitly used the number of discharged patients as their denominator. Seven studies that used patients affected by at least one ME as their numerator are summarised below [23, 72, 75, 87, 89, 96, 99]. Across five studies from three settings that reported ME rates per discharged patient [23, 87, 89, 96, 99], a median of 53\% [IQR 33-60.5\%] of adult and elderly patients experienced MEs post-discharge. Two prospective studies [96, 99] out of these five reported ME rates for patients discharged home as $47-53 \%$ of discharged patients. A range of $19-53 \%$ of elderly discharged patients $(n=2)$ experienced at least one ME post-discharge [23, 96].

One study [72] reported that one or more prescribing errors affected $43 \%$ of discharged patients. Another study [87] reported that $3.5 \%$ of discharge medications were affected by at least one monitoring error post-discharge. One study [61] reported ME and medication administration error rates for infants as $66.3 \%$ and $54.0 \%$ of discharged patients, respectively.

\subsection{Unintentional Medication Discrepancy Studies}

In total, 14 studies reported data concerning the frequency of UMDs [49, 50, 57, 59, 60, 66, 70, 74, 83, 84, 88, 93, 95, 98]. Three studies [83, 84, 93] used an established UMD definition, seven $[49,50,59,60,70,74,95]$ developed their own and four [57, 66, 88, 98] did not report any definition.

The majority of included studies explicitly used the number of discharged patients affected by at least one event as their numerator, except two studies that used the number of 


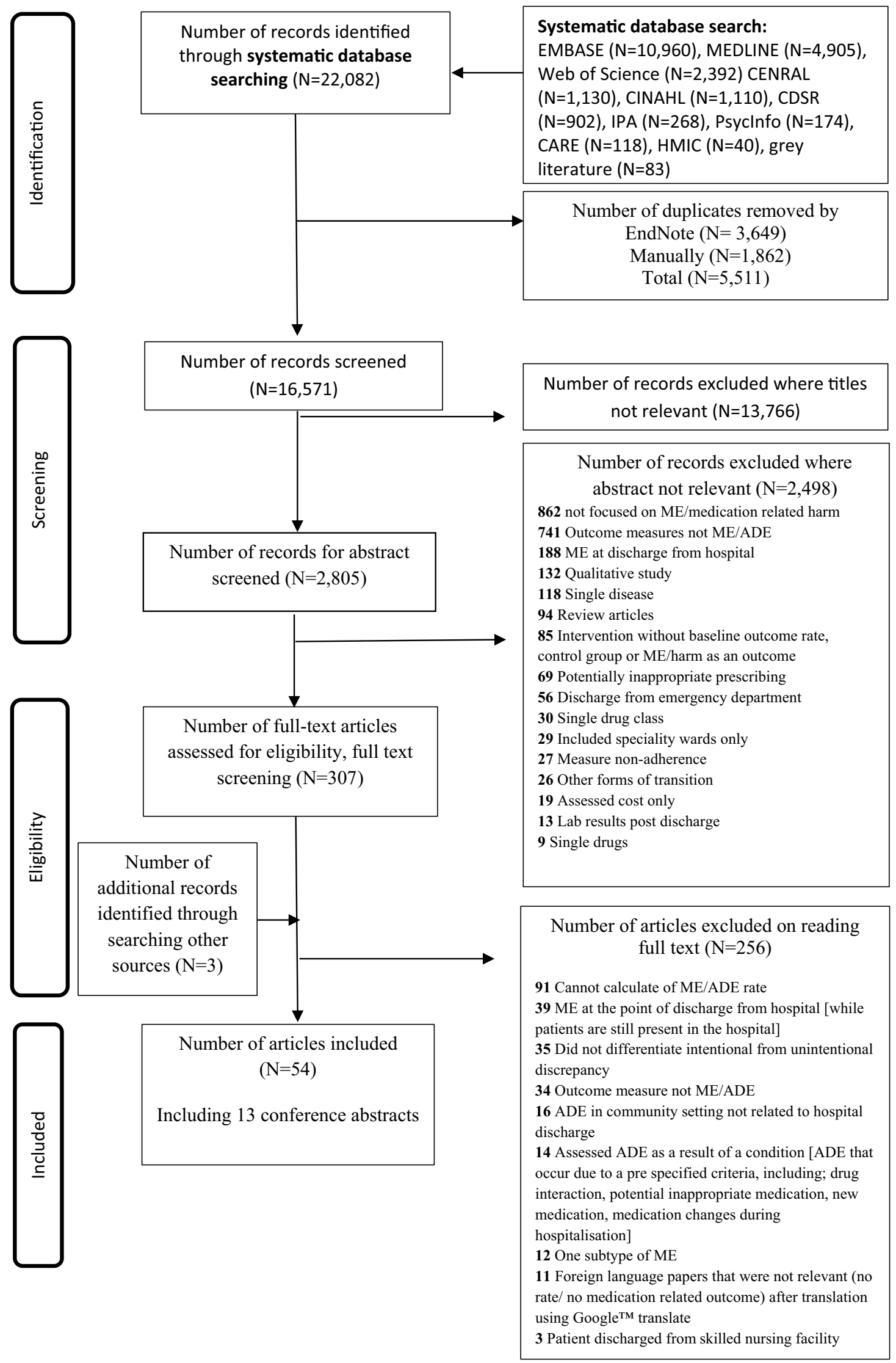


४Fig. 1 Preferred Reporting Items for Systematic Review and MetaAnalysis (PRISMA) flow diagram. $A D E$ adverse drug event, $C D S R$ Cochrane Database of Systematic Reviews, CENTRAL Cochrane Central Register of Controlled Trials, CINAHL Cumulative Index to Nursing and Allied Health Literature, DARE Database of Abstracts of Reviews of Effects, HMIC Health Management Information Consortium, IPA International Pharmaceutical Abstracts, $M E$ medication error

discharge medications affected by one or more UMDs [49, 50]. These latter studies $[49,50]$ reported that $11-52.7 \%$ of individual prescribed medications had at least one UMD post-discharge. One study [95] reported that at least one UMD affected $12 \%$ of discharged paediatric patients. Across 11 studies $[57,59,60,66,70,74,83,84,88,93$, 98], a median rate of 50\% (IQR 39-76) of adult and elderly patients experienced at least one UMD post-discharge (range 14-93.5\%). Four studies [59, 70, 74, 93] that used a telephone follow-up among data collection methods, and five studies using case note screening [60, 66, 83, 84, 98] reported the rate of UMD to be $65-93.5 \%$ and $14-76 \%$, respectively, per adult and elderly patient discharged. A range of $36.5-93.5 \%$ of discharged elderly patients $(n=5)$ experienced UMDs post-discharge [60, 66, 83, 88, 93].

\subsection{Adverse Drug Events}

Seventeen studies $[24,48,54-56,61,67,69,70,74,78,80$, $82,86,92,94,97]$ reported ADE rates post-hospital discharge, 17 studies $[24,51-53,58,62-64,68,71,73,76,77$, $79,81,82,91]$ reported non-preventable ADE rates (ADRs) post-discharge, one study [24] reported both.

\subsubsection{Non-preventable Adverse Drug Events (Adverse Drug Reactions)}

Three studies $[62,64,68]$ used the ADR definition proposed by the WHO in 1972, nine studies [51, 53, 58, 63, $71,76,79,81,82]$ used a broader DRP definition that included ADRs, and three $[52,77,91]$ did not state a definition.

All studies explicitly used the number of discharged patients as their denominator. Across five studies [24, 58, $64,73,91]$ that used patients affected by events as their numerator, a median of $27 \%$ (IQR 18-40.5) of adult and elderly patients experienced one or more ADRs post-hospital discharge. Two studies [24, 73] that used a telephone follow-up as the most common data collection method reported the rate of ADRs post-discharge to be 20.4-27\% of discharged patients. A range of $27-51 \%$ of elderly discharged patients $(n=3)$ experienced ADRs post-discharge [24, 58, 64].

\subsubsection{Adverse Drug Events}

Four studies $[61,74,80,86]$ used the ADE definition proposed by Bates et al. [32]. Seven studies [48, 55, 67, 78, 92, 94, 97] did not formally define ADEs. All studies explicitly used the number of discharged patients as their denominator. One study [86] reported the rate of post-discharge ADEs as 9\% of paediatric patient hospital discharges. One study [82] reported the mean number of ADEs per discharged patient as 3. Across seven studies $[24,54,55,61,69,74,94]$ that used patients affected by at least one event as their numerator, the median ADE rate was found to be 19\% [IQR 16-24\%] of adult and elderly patients experiencing one or more ADEs post-discharge. Two studies $[74,80]$ reported that between 11 and $16 \%$ of discharged patients experienced one or more preventable ADEs.

Five studies $[24,54,55,69,74]$ that used telephone follow-up interviews among data collection methods reported 11-37\% (median 20.3\%, IQR 13.5-30.5) of adult and elderly patients discharged experienced one or more ADEs. Two studies $[61,94]$ that used case note screening among data collection methods reported that $18.7-18.9 \%$ of discharged patients were affected by ADEs post-hospital discharge. Two studies $[54,78]$ that adapted Bates definition of ADEs and used the same data collection method reported that 11-16\% of adult and elderly patients had at least one ADE after hospital discharge. The highest reported ADE rate was 37\% of patients using a telephone interview method in one study [24] in the UK. A range of 18.7-37\% of elderly discharged patients $(n=4)$ experienced ADEs post-discharge [24, 55, $61,94]$. Table 4 summarises outcome rates of the included studies per patient population.

\subsection{Severity of Events}

Eighteen [24, 54-56, 59, 61, 62, 64, 66, 69, 70, 72, 78, 80, $88,91,94,95](18 / 54,33.3 \%)$ studies reported severity data of identified outcome measures, including one ME study [72], three ADR studies [62, 64, 91], nine ADE studies [24, $54-56,61,69,78,80,94]$ and five UMD studies [59, 66, 70, $88,95]$. Seven studies [54, 61, 62, 64, 72, 78, 80] reported severity assessment based on existing rating scales published in the literature. Of these, three studies $[54,61,78]$ used the severity rating proposed by Bates et al. [32], with various other scales being used by remaining studies.

Comparability of the severity of events was limited because of heterogeneity across studies in presenting severity of event data (e.g. number of patients affected by one or more serious incidents, or number of serious incidents), severity rating scale, and the small number of included studies particularly when divided across patient populations. One study reported that $86 \%$ of adult patients affected by MEs were considered to be moderate harm events [72]. Among 
Table 2 Characteristics of included studies

\begin{tabular}{|c|c|c|c|}
\hline Characteristics & $\begin{array}{l}\text { Number of studies } \\
(n=54)\end{array}$ & $\%$ & References \\
\hline \multicolumn{4}{|l|}{ Country } \\
\hline USA & 17 & 31.5 & {$[52,54-57,61,70,74,76,78,79,82,89,90,94,96,97]$} \\
\hline UK & 7 & 13 & {$[24,49,50,59,87,95,98]$} \\
\hline Norway & 4 & 7.4 & {$[60,65,81,86]$} \\
\hline Canada & 3 & 5.5 & {$[53,63,92]$} \\
\hline The Netherlands & 2 & 3.7 & {$[58,88]$} \\
\hline Australia & 2 & 3.7 & {$[48,77]$} \\
\hline France & 2 & 3.7 & {$[62,99]$} \\
\hline Sweden & 2 & 3.7 & {$[66,83]$} \\
\hline Switzerland & 2 & 3.7 & {$[23,51]$} \\
\hline India & 2 & 3.7 & {$[68,75]$} \\
\hline Italy & 1 & 1.8 & {$[84]$} \\
\hline New Zealand & 1 & 1.8 & {$[85]$} \\
\hline Belgium & 1 & 1.8 & [93] \\
\hline Croatia & 1 & 1.8 & {$[64]$} \\
\hline Ireland & 1 & 1.8 & {$[72]$} \\
\hline Egypt & 1 & 1.8 & {$[67]$} \\
\hline Europe $^{\mathrm{a}}$ & 1 & 1.8 & [71] \\
\hline Jordan & 1 & 1.8 & {$[73]$} \\
\hline Oman & 1 & 1.8 & {$[80]$} \\
\hline Sri Lanka & 1 & 1.8 & [91] \\
\hline Saudi Arabia & 1 & 1.8 & {$[69]$} \\
\hline \multicolumn{4}{|l|}{ Publication year } \\
\hline 1990-9 & 3 & 5.5 & {$[49,50,55]$} \\
\hline $2000-9$ & 8 & 14.8 & {$[48,54,62,63,71,74,83,86]$} \\
\hline $2010-19$ & 43 & 79.6 & {$[23,24,51-53,56-61,64-70,72,73,75-82,84,85,87-99]$} \\
\hline \multicolumn{4}{|l|}{ Patient demographics } \\
\hline Adults & 28 & 51.8 & {$[49-52,54,56,57,59,60,67,69-74,76-82,84,87,91,98,99]$} \\
\hline Elderly $^{\mathrm{b}}$ & 18 & 33.3 & {$[23,24,48,53,55,58,61,63-66,68,83,88,90,93,94,96]$} \\
\hline Paediatric & 3 & 5.5 & {$[75,86,95]$} \\
\hline All age groups & 1 & 1.8 & [62] \\
\hline Not specified & 4 & 7.4 & {$[85,89,92,97]$} \\
\hline \multicolumn{4}{|l|}{ Study design } \\
\hline Prospective & 46 & 85.2 & {$[23,24,48-52,54,55,57-60,62-78,80,81,83,85,86,88-93,95-99]$} \\
\hline Retrospective & 8 & 14.8 & {$[53,56,61,79,82,84,87,94]$} \\
\hline \multicolumn{4}{|l|}{ Study setting ${ }^{\mathrm{f}}$} \\
\hline Home & 41 & 75.9 & {$[24,49-54,56-59,61,62,64,65,67-72,74-82,85-88,92,94-99]$} \\
\hline Home care ${ }^{c}$ & 5 & 9.2 & {$[23,24,55,60,66]$} \\
\hline Nursing home & 3 & 5.5 & {$[60,66,98]$} \\
\hline Other $^{\mathrm{d}}$ & 5 & 9.2 & {$[48,63,83,84,89]$} \\
\hline Not specified & 3 & 5.5 & {$[90,91,93]$} \\
\hline \multicolumn{4}{|l|}{ Study focus ${ }^{\mathrm{g}}$} \\
\hline ME & 12 & 21.8 & {$[23,65,71,72,75,85,87,89,90,96,97,99]$} \\
\hline UMD & 14 & 25.9 & {$[49,50,57,59,60,66,70,74,83,84,88,93,95,98]$} \\
\hline ADR & 17 & 30.9 & {$[24,51-53,58,62-64,68,71,73,76,77,79,81,82,91]$} \\
\hline ADE & 17 & 30.9 & {$[24,48,54-56,61,67,69,70,74,78,80,82,86,92,94,97]$} \\
\hline \multicolumn{4}{|l|}{ Data collection method ${ }^{\mathrm{h}}$} \\
\hline Screen case note & 43 & 79.6 & {$[23,24,48-52,54,56-61,63-72,74-87,89,93-95,98]$} \\
\hline Telephone follow-up & 25 & 46.2 & {$[24,52,54,55,59,63,65,67-74,76,78-80,90,93,95,97,99]$} \\
\hline
\end{tabular}


Table 2 (continued)

\begin{tabular}{lrrl}
\hline Characteristics & $\begin{array}{l}\text { Number of studies } \\
(n=54)\end{array}$ & \multicolumn{1}{l}{ References } \\
& 12 & 22.2 & {$[49,50,53,58,63,64,71,81,88,92,95,96]$} \\
Home visit & 16 & 29.6 & {$[23,56-58,62,64,71,75-77,82,86,87,90,92,96]$} \\
Other $^{\mathrm{e}}$ & 1 & 1.8 & {$[91]$} \\
Not specified & & \\
Profession of data collector ${ }^{\mathrm{i}}$ & 27 & 50 & {$[24,52,53,56,60,61,63,66,69,71,73,76,77,79,81-83,85-87,89,90$,} \\
Pharmacist & & $92,94,97-99]$ \\
& 6 & 11.1 & {$[54,62,64,70,84,88]$} \\
Physician & 5 & 9.2 & {$[23,70,78,84,96]$} \\
Nurse & 7 & 12.9 & {$[55,58,59,65,67,74,80]$} \\
Research assistant & 1 & 1.8 & {$[51]$} \\
Pharmacy student & 10 & 18.5 & {$[48-50,57,68,72,75,91,93,95]$} \\
Not specified & & \\
Follow-up period, days ${ }^{\mathrm{j}}$ & 20 & 37 & {$[23,49,50,53,57,60,66,69,71,72,76,82,85,86,88,90,92,93,97,99]$} \\
$1-15$ & 19 & 35.1 & {$[52,54-56,58,59,62-64,67,70,73,74,79,80,83,95,96]$} \\
$16-30$ & 11 & 20.3 & {$[24,48,61,68,77,78,81,87,91,94,98]$} \\
$31-180$ & 4 & 7.4 & {$[51,75,84,89]$} \\
Not specified & &
\end{tabular}

$A D E$ adverse drug event, $A D R$ adverse drug reaction, $M E$ medication error, $U M D$ unintentional medication discrepancy

${ }^{a}$ One study included data from six countries in Europe including; Austria, Germany, Denmark, Spain, The Netherlands and Portugal

${ }^{\mathrm{b}}$ Among the 18 studies, nine studies included patients aged $\geq 65$ years [21, 53, 55, 61, 64-66, 83, 94], one study included patients aged $\geq 64$ years [23], three studies included patients aged $\geq 60$ years [58, 63, 68] and five studies did not mention a cut-off age [48, 88, 90, 93, 96]. Among the five studies that did not mentioned the cut-off age, two studies mentioned the mean age and referred to patients as older adults [48, 88], one study included patients discharged from a geriatric ward [93], one study included veteran geriatric patients [96] and one study included Medicare Advantage patients [90]

${ }^{\mathrm{c}}$ Providing care at patient home

${ }^{\mathrm{d}}$ Long-term care facility, local care settings, local care home programme, outpatient rehabilitation facility, community healthcare

${ }^{\mathrm{e}}$ Follow-up visit at hospital/clinic, medication reconciliation post discharge, general practitioner database, reporting of incident, questionnaire, interview at community pharmacy, medication reconciliation (via secure messaging at home), reporting of incident

${ }^{\mathrm{f}}$ Studies could have patient discharged to more than one location

${ }^{\mathrm{g}}$ Study focus could be more than one outcome

${ }^{\mathrm{h}}$ Studies could have more than one data collection method

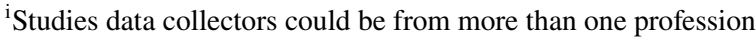

${ }^{\mathrm{j}}$ Follow-up period for the outcome of interest

patients affected by ADRs, three studies reported that serious ADRs affected $6.9 \%, 47 \%$ and $60 \%$ of elderly, adult and all age groups patients, respectively [62, 64, 91]. Among patients affected by ADEs post-hospital discharge, serious ADEs were reported to affect $13.3 \%$ of adult patients, and $81 \%$ of elderly patients in two studies [24, 54]. Four studies reported that the median rate of serious ADEs was found to be $29 \%$ (IQR 21-38.5\%) of adult and elderly patients experiencing one or more ADEs post-discharge [61, 69, 80, 94]. Among patients affected by UMDs, three studies reported that between 25 and $34 \%$ of elderly patients [66, 88], and $63.3 \%$ of paediatric patients were affected by moderate harm events [95]. Two studies reported that 33-38\% of UMDs identified post-hospital discharge as associated with a high potential of harm in adult patients [59, 70]. Appendix 9 of the ESM includes a summary of severity data of the included studies.

\subsection{Medication Involved in Unintentional Medication Discrepancies/Adverse Drug Events}

Fourteen studies $[24,53-56,61,62,64,70,71,78,79$, $82,91]$ reported data regarding individual medications or drug classes associated with UMDs $(n=1)$ and ADEs $(n=14)$. Studies evaluating MEs did not report data regarding medications involved. The most common drug classes that were reported to lead to post-discharge ADEs across 14 studies [24, 53-56, 61, 62, 64, 70, 71, 78, 79, 82, 91] were antibiotics, antidiabetics, analgesics and cardiovascular drugs (common subclasses were anti-hypertensive and anticoagulant medications). Only one study [64] reported a 


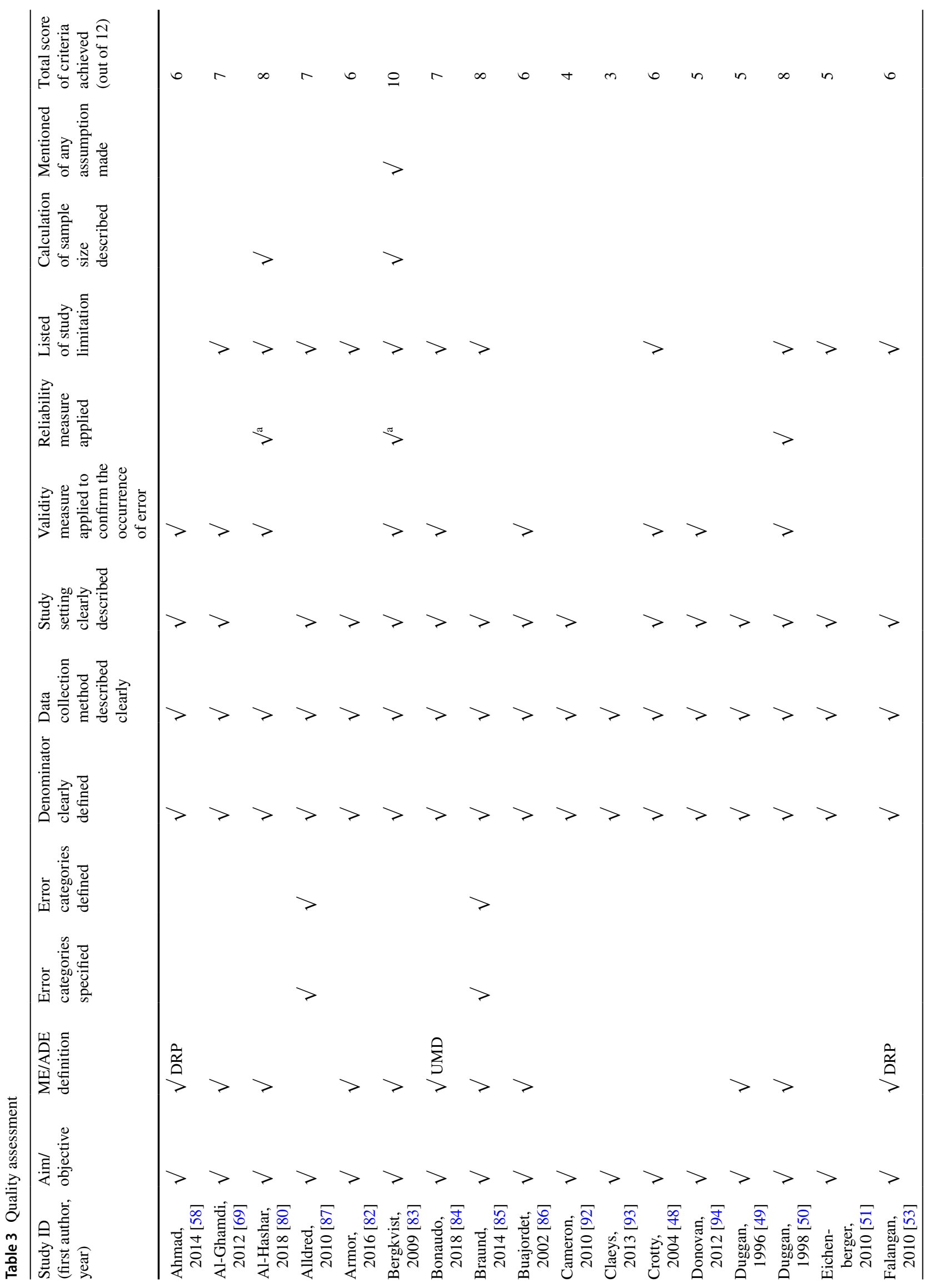




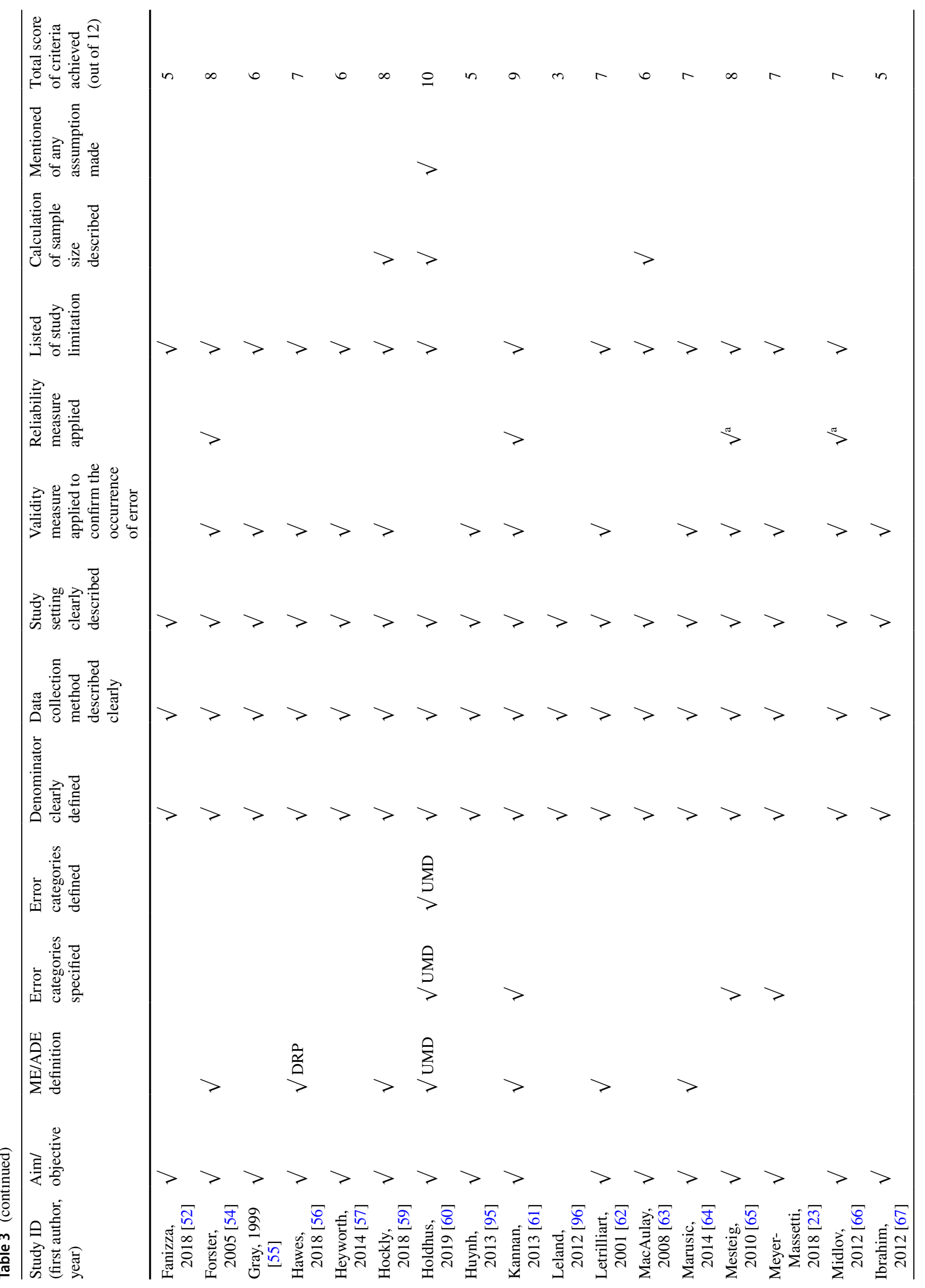




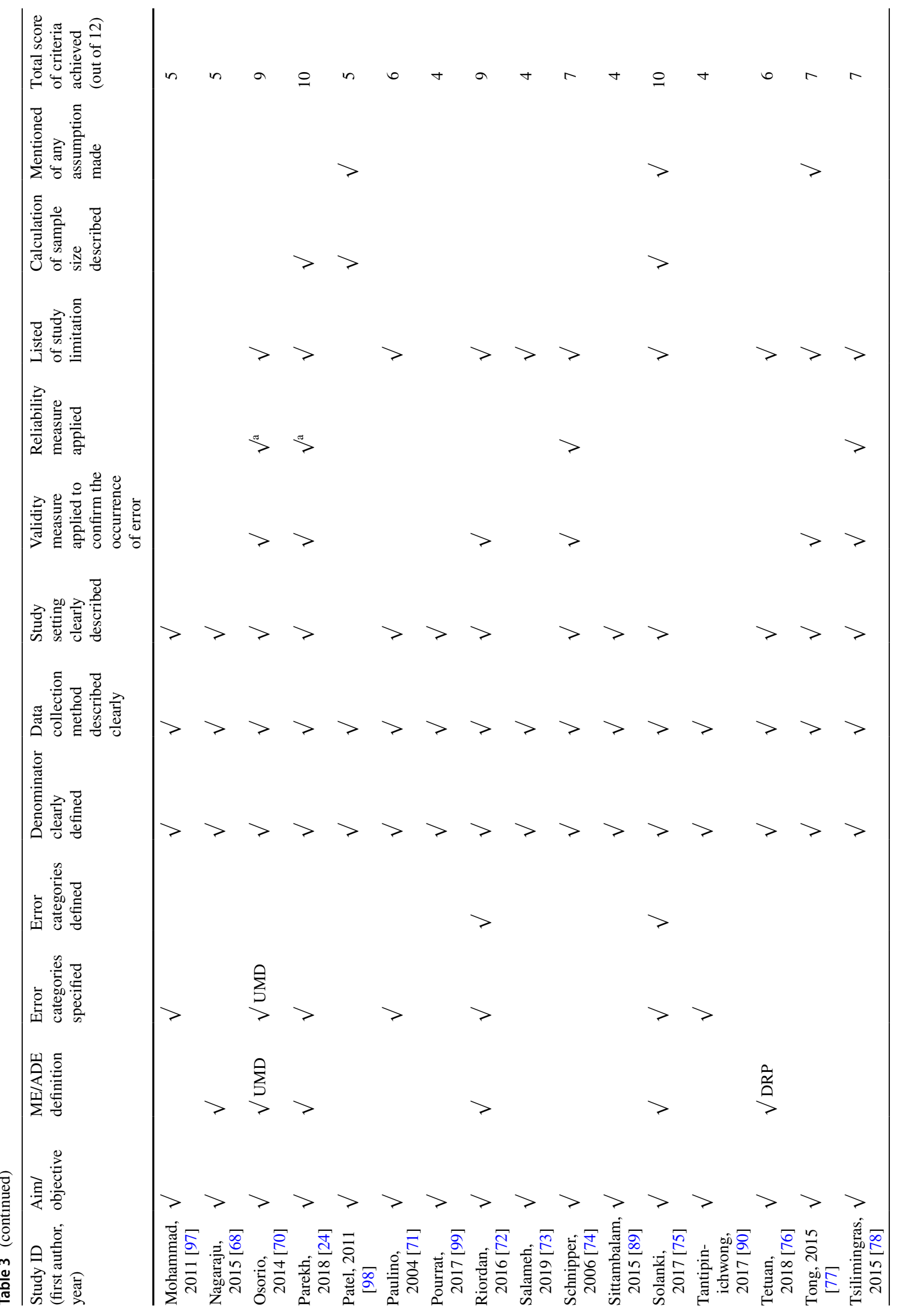




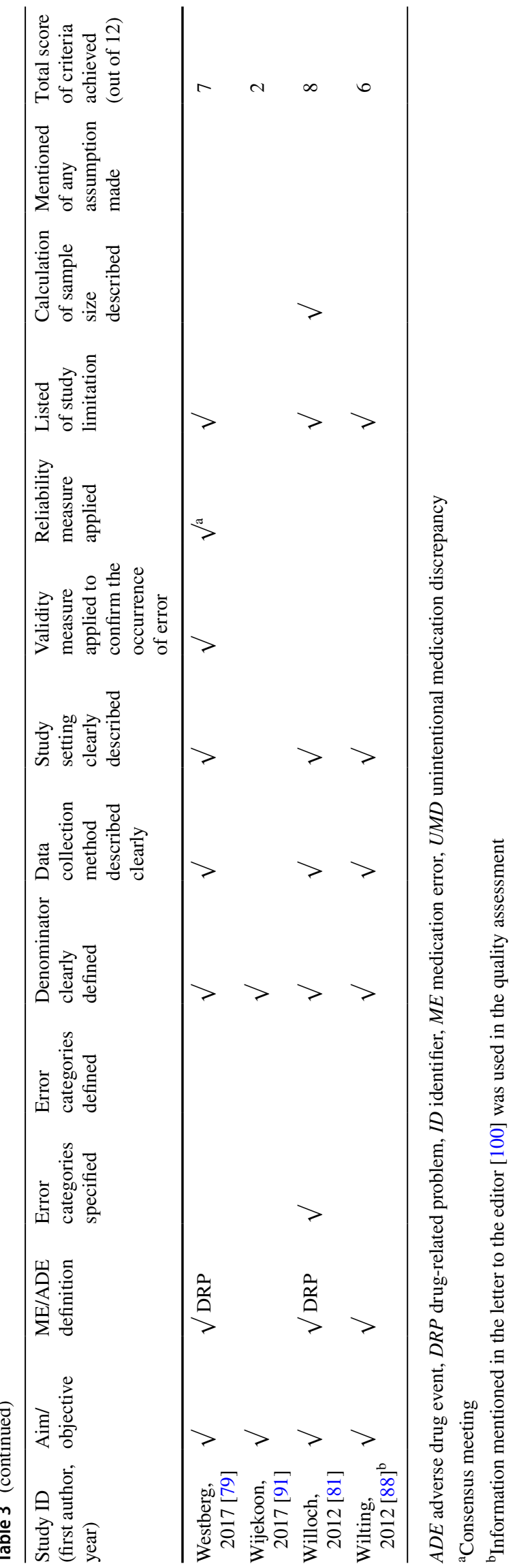

statistical method to formally associate the prescription of warfarin with ADEs. Appendix 10 of the ESM summarises medications and medication classes that were reported to be involved in UMDs/ADEs, classified according to the British National Formulary system [102].

\section{Discussion}

\subsection{Main Findings}

This is the first systematic review of published international evidence concerning the epidemiology of MEs and ADEs post-hospital discharge across population groups. We have identified that medication poses a frequent and enduring risk to patient safety following discharge from hospital, which reinforces care transfer being a WHO Global Patient Safety Challenge priority for action. We found across included studies that a median of one in two adult and elderly patients are affected by at least one ME post-hospital discharge, one in two affected by one or more UMD, and one in five affected by one or more ADEs (the median rate of MEs, UMDs and ADEs post-hospital discharge was 53\% [IQR 33-60.5] $(n=5), 50 \%$ [IQR 39-76] $(n=11)$ and 19\% [IQR 16-24] $(n=7)$, respectively). We also reported emerging evidence of the nature of these risks, with a median of nearly one third of adult and elderly patients affected by clinically serious ADEs post-hospital discharge and medication classes most commonly reported with ADEs as antibiotics, antidiabetics, analgesics and cardiovascular drugs.

The focus of this review was on both process measures such as MEs and outcome measures such as ADEs [103]. Medication errors that occur irrespective of harm are an important window into the safety of healthcare systems. This helps understand what can turn errors into ADEs where risks may lie dormant and what patterns emerge that may support learning to prevent harmful events occurring in the future.

This review has revealed that similar median rates of ADEs and/or UMDs occur post-hospital discharge to those reported on hospital admission [104], during inpatient stay [105] and whilst residing in ambulatory care [106]. This indicates that the transition of care from hospital to home should be considered an equal priority to other stages of the patient journey by researchers and healthcare policy makers. Evidence indicates that hospital discharge has been the subject of attention in patient safety policy documents [13, 22, 107-109], where these documents are translating into action on the ground in the form of new initiatives [110].

We have observed that research has been accelerating in the field of medication safety post-hospital discharge since the year 2010. A previous review published in 2010 [20] found that ADEs post-hospital discharge affected $20 \%$ of elderly patients $(n=1)$ [55], while our review updates and 


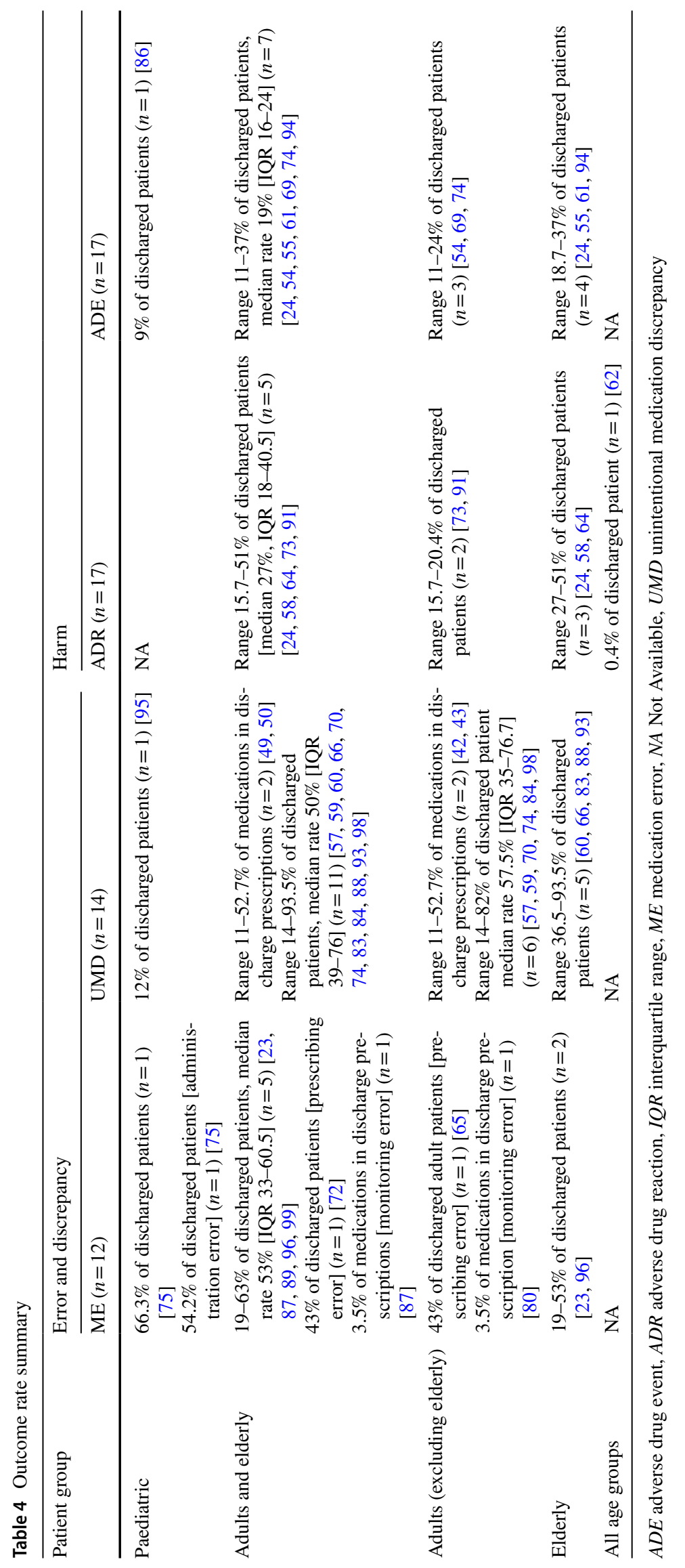


strengthens this evidence with a rate of $18.7-37 \%$ of discharged elderly $(n=4)[24,55,61,94]$. Our review found that the median rate of MEs and ADEs is higher in the elderly population. While two previous systematic reviews of medication safety incidents post-hospital discharge in the elderly were informative [20,21], they examined the elderly in isolation whereas our review compared this patient group with other populations to help determine priorities. Older patients may be a high-risk group to experience MEs and ADEs owing to factors including pharmacodynamic/ pharmacokinetics differences, additional co-morbidities and polypharmacy [111-115]. It also reinforces the recent WHO Medication Safety in Transitions of Care-Technical Report, which recommend targeting medication reconciliation interventions to high-risk areas [116].

Many studies included in this review report MEs and medication discrepancies following the evaluation and comparison of medication lists in hospital case notes and discharge prescriptions to data obtained from interviewing patients in the community setting following hospital discharge. However, these studies often omitted data from primary care records post-hospital discharge, which may have led to inaccurate ME/UMD rates being reported, instead relying primarily on patient-reported data [59].

\subsection{Implications of Findings}

Our systematic review identifies that the burden of MEs and ADEs following hospital discharge is comparatively underresearched in paediatric and nursing/care home settings. This is important as evidence indicates that medication safety challenges for these patient groups exist both during hospitalisation [46] and at the point of discharge from hospital [117]. Further work to explore the burden and causes of medication safety challenges following transfer to nursing and care homes is also required as unique factors have been reported to complicate these care transitions, including the older age of patients and their elevated severity of illness/care needs [118], as well as apparent challenges with accountability and communication among staff $[119,120]$.

The majority of studies $(47 / 54,87 \%)$ included in this review originated from developed nations (in particular, the USA and UK) and there was limited evidence from developing countries (e.g. Africa and South America, $n=1$ study) [121]. Low levels of patient support post-hospital discharge as a result of underdeveloped primary care services have been reported in such nations [122]. In addition, with the exception of the USA, nations that have multiple studies included in our review rarely contained data across all our outcome measures, which limits a global assessment of risk.

Studying preventable ADEs is important as they are amendable to intervention (unlike many ADRs) [123] and may better inform the design of system improvements alongside an understanding of other preventable events such as MEs and UMDs. A recent systematic review and meta-analysis of preventable harm in healthcare worldwide reported a pooled prevalence of $6 \%$, with medications a chief contributor to this harm [123]. In this review, only two studies measured preventable ADEs to be between 11 and 16\% of discharged patients. Further exploration of the burden and causes of preventable ADEs would further the WHO Third Global Patient Safety Challenge: Medication Without Harm agenda, which aims to reduce severe avoidable patient harm by $50 \%$ and names care transitions as a key area to address [4].

This systematic review found that medication classes most implicated in harm post-hospital discharge were cardiovascular, analgesic, antibiotic, and antidiabetic medications. Similar findings have been reported by other literature $[106,124,125]$ investigating medication-related harm in ambulatory settings and medication-related causes for hospital admission. These medication groups may become a focus of attention by researchers and healthcare staff as potential targets for remedial action that could improve patient outcomes [126]. Our review can be used to inform the development and update a medication-related harm prediction tools that focus on post-discharge risk [127], as well as to update and reinforce prescribing and monitoring quality indicators in primary care settings [128-130]. Elsewhere these findings could also inform ongoing use of the national health services (National Health Service) New Medicines Service in community pharmacies in the UK [131], which involves counselling the patient starting new medications for chronic diseases including diabetes mellitus and hypertension and for those starting new anticoagulant medications. Our findings suggest that longer term analgesic medications could be considered for inclusion in the New Medicines Service.

Our ability to make direct comparisons between included studies was limited because of the observed heterogeneity in country of origin, patient groups studied, data collection methods and outcome definitions. Other systematic reviews of MEs [46, 132, 133] and ADEs [45, 106, 134] also report similar limitations with this body of literature. For example, we observed no pattern in included studies with regard to the follow-up period post-discharge and the outcome rate or their definitions. There is currently no consensus regarding the specific time point to stop collecting data [135]. There is also wide variation and disagreement in time frame definitions used in research concerning hospital readmission $[1,136,137]$. This suggests that greater consistency and standardisation of methods (for example, standardisation of the outcome definition via the Delphi technique [138]) are required between studies investigating transfer of care to enhance comparability of results and ultimately the development of remedial interventions. Aside from standardisation of methods, there is also a need to improve the quality 
of reporting in studies of care transitions as few studies reported outcome definitions and other essential information. A similar deficit in the quality of reporting of medication safety studies [47] and observational epidemiological studies have been noted previously [139], where standard tools for reporting to a higher standard were proposed. However, most studies were rated as moderate or high quality.

It is anticipated from our identified rate of error/harm that the cost of "no action taken" is high in terms of a patient's subsequent use of the healthcare services post-hospital discharge. A number of reviews have been published that evaluated interventions (including medication reconciliation, community pharmacy involvement and electronic communication interventions) to reduce MEs and ADEs post-discharge [140-146]. However, none have reported consistent reductions in these outcomes. Understanding the epidemiology and nature of medication safety challenges post-hospital discharge paves the way for research to examine the causes, where in-depth study of aetiology in this area could support the development of interventions [147, 148]. Studies have been limited to incident report analysis [13,149] and staff surveys that report that communication deficits have been implicated in ME/ADEs post-discharge [19]. In addition, attention has recently been drawn to the patient's experience of hospital discharge, where patients reported pressured discharges, the complicated nature of discharge, communication issues and healthcare system fragmentation (e.g. lack of shared electronic records across care boundaries affected their medication management post-discharge $[9,137,150$, 151]). Indeed, recent research has included the valuable patient perspective on discharge and how they may manage their medication effectively $[8,150-155]$. This research should be used by academics, policymakers and healthcare staff alongside the findings of this review and explorations of the causes of MEs/ADEs post-discharge from the health provider perspective to connect patients and health systems together to reduce medication safety risks from a more holistic perspective.

\subsection{Strengths and Limitations}

A comprehensive search strategy was conducted across the grey literature and ten electronic databases covering the modern healthcare era, with search criteria involving no restrictions on language, study country or patient demographics. We also presented a transparent review methodology with reporting following the PRISMA approach, and an author contact section [156] to reduce reporting bias. We also performed a quality assessment of included studies to help frame our findings in context.

However, this study has a number of limitations that affected the internal validity including no independent quality assessment, and single author screening of citations, which could have led to the omission of relevant studies (though uncertain cases were discussed amongst the research team) [157]. A meta-analysis of outcome rate data was also not possible because of heterogeneity of included data.

\section{Conclusions}

This is the first known comprehensive systematic review of the burden and nature of MEs and medication-related harm following hospital discharge across general populations, and informs global efforts directed toward understanding and addressing medication-related morbidity associated with care transitions. Medication errors and ADEs have been found to be common following hospital discharge, but a detailed comparison between studies was limited because of differences in the design of included studies. Despite this, a number of important targets were identified for future study that could guide the development of successful remedial interventions and move forward the global safety agenda.

Acknowledgements We are thankful to Ghadah H. Alshehri for her help with creating the systematic review protocol.

Author Contributions All authors contributed to the study conception and design. Systematic review planning, data extraction and data analysis were led and performed by FAA, and supported by RNK and DS. Citation screening and identification were completed by FAA. The first draft of the manuscript was written by FAA and all authors commented on previous versions of the manuscript. All authors read and approved the final manuscript.

Data Availability All data generated and analysed during this study are included in this published article and its supplementary information files.

\section{Compliance with Ethical Standards}

Funding Fatema A. Alqenae gratefully acknowledges the Kuwait Civil Service Commission for funding her PhD programme at the University of Manchester. The funders had no role in the study design, data collection and analysis, decision to publish, or preparation of the manuscript.

Conflict of interest Fatema A. Alqenae, Douglas Steinke and Richard $\mathrm{N}$. Keers have no conflicts of interest that are directly relevant to the content of this study.

Open Access This article is licensed under a Creative Commons Attribution-NonCommercial 4.0 International License, which permits any non-commercial use, sharing, adaptation, distribution and reproduction in any medium or format, as long as you give appropriate credit to the original author(s) and the source, provide a link to the Creative Commons licence, and indicate if changes were made. The images or other third party material in this article are included in the article's Creative Commons licence, unless indicated otherwise in a credit line to the material. If material is not included in the article's Creative Commons licence and your intended use is not permitted by statutory 
regulation or exceeds the permitted use, you will need to obtain permission directly from the copyright holder. To view a copy of this licence, visit http://creativecommons.org/licenses/by-nc/4.0/.

\section{References}

1. Kim C, Flanders S. In the clinic: transitions of care. Ann Intern Med. 2013;5:ICT3-1.

2. Moore C, Wisnivesky J, Williams S, McGinn T. Medical errors related to discontinuity of care from an inpatient to an outpatient setting. J Gen Intern Med. 2003;18:646-51.

3. Kattel S, Manning DM, Erwin PJ, Wood H, Kashiwagi DT, Murad MH. Information transfer at hospital discharge: a systematic review. J Patient Saf. 2020;16(1):e25-e33.

4. World Health Organization. Global patient safety challenge: medication without harm. 2017; p. 1-16. http://apps.who.int/ iris/bitstream/10665/255263/1/WHO-HIS-SDS-2017.6-eng. pdf?ua $=1 \& u a=1$. Accessed 26 Jan 2020.

5. Cornish PL, Tam V, Shadowitz S, Marchesano R, Juurlink DN, Etchells EE, et al. Unintended medication discrepancies at the time of hospital admission. Arch Intern Med. 2005;165:424-9.

6. Ong S, Fernandes O, Cesta A, Bajcar J. Drug-related problems on hospital admission: relationship to medication information transfer. Ann Pharmacother. 2006;40:408-13.

7. Greysen SR, Hoi-Cheung D, Garcia V, Kessell E, Sarkar U, Goldman L, et al. "Missing pieces": functional, social, and environmental barriers to recovery for vulnerable older adults transitioning from hospital to home. J Am Geriatr Soc. 2014;62:1556-61.

8. Fylan B, Armitage G, Naylor D, Blenkinsopp A. A qualitative study of patient involvement in medicines management after hospital discharge: an under-recognised source of systems resilience. BMJ Qual Saf. 2018;27:539-46.

9. Fylan B, Marques I, Ismail H, Breen L, Gardner P, Armitage G, et al. Gaps, traps, bridges and props: a mixed-methods study of resilience in the medicines management system for patients with heart failure at hospital discharge. BMJ Open. 2019;9:1-11.

10. Himmel W, Kochen M, Sorns U, et al. Drug changes at the interface between primary and secondary care. Int J Clin Pharmacol Ther. 2004;42:103-9.

11. Frydenberg K, Brekke M. Poor communication on patients' medication across health care levels leads to potentially harmful medication errors. Scand J Prim Health Care. 2012;30:234-40.

12. Witherington EMA, Pirzada OM, Avery AJ. Communication gaps and readmissions to hospital for patients aged 75 years and older: observational study. Qual Saf Health Care. 2008;17:71-5.

13. NHS England. Patient safety alert: stage one: warning: risks arising from breakdown and failure to act on communication during handover at the time of discharge from secondary care. 2014: p. 4-5. https://www.england.nhs.uk/wp-content/uploads/2014/08/ psa-imp-saf-of-discharge.pdf. Accessed 26 Jan 2020.

14. El Morabet N, Uitvlugt EB, van den Bemt BJF, van den Bemt PMLA, Janssen MJA, Karapinar-Çarkit F. Prevalence and preventability of drug-related hospital readmissions: a systematic review. J Am Geriatr Soc. 2018;66:602-8.

15. Perren A, Donghi D, Marone C, Cerutti B. Economic burden of unjustified medications at hospital discharge. Swiss Med Wkly. 2009;139:430-5.

16. Mills PR, Weidmann AE, Stewart D. Hospital electronic prescribing system implementation impact on discharge information communication and prescribing errors: a before and after study. Eur J Clin Pharmacol. 2017;73:1279-86.
17. Bishop MA, Cohen BA, Billings LK, Thomas EV. Reducing errors through discharge medication reconciliation by pharmacy services. Am J Health Syst Pharm. 2015;72:S120-6.

18. Michaelsen M, McCague P, Bradley C, Sahm L. Medication reconciliation at discharge from hospital: a systematic review of the quantitative literature. Pharmacy. 2015;3:53-71.

19. Ensing HT, Koster ES, van Berkel PI, van Dooren AA, Bouvy ML. Problems with continuity of care identified by community pharmacists post-discharge. J Clin Pharm Ther. 2017;42:170-7.

20. Garcia-Caballos M, Ramos-Diaz F, Jimenez-Moleon JJ, BuenoCavanillas A. Drug-related problems in older people after hospital discharge and interventions to reduce them. Age Ageing. 2010;39:430-8.

21. Parekh N, Ali K, Page A, Roper T, Rajkumar C. Incidence of medication-related harm in older adults after hospital discharge: a systematic review. J Am Geriatr Soc. 2018;66:1812-22.

22. Royal Pharmaceutical Society. Keeping patients safe when they transfer between care providers: getting the medicines right. 2012. https://www.rpharms.com/Portals/0/RPS-document-libra ry/Open-access/Publications/Keeping-patients-safe-transfer-ofcare-report.pdf. Accessed 21 Feb 2020.

23. Meyer-Massetti C, Hofstetter V, Hedinger-Grogg B, Meier CR, Guglielmo BJ. Medication-related problems during transfer from hospital to home care: baseline data from Switzerland. Int J Clin Pharm. 2018;40:1614-20.

24. Parekh N, Ali K, Stevenson JM, Davies JG, Schiff R, Van der Cammen $\mathrm{T}$, et al. Incidence and cost of medication harm in older adults following hospital discharge: a multicentre prospective study in the UK. Br J Clin Pharmacol. 2018;84:1789-97.

25. Moher D, Liberati A, Tetzlaff J, Altman DG, et al. Preferred reporting items for systematic reviews and meta-analyses: the PRISMA statement. BMJ. 2009;339:b2535.

26. Bramer WM, Rethlefsen ML, Kleijnen J, Franco OH. Optimal database combinations for literature searches in systematic reviews: a prospective exploratory study. Syst Rev. 2017;6:1-12.

27. Haber SL, Fairman KA, Sclar DA. Principles in the evaluation of systematic reviews. Pharmacotherapy. 2015;35:1077-87.

28. Benzies KM, Premji S, Hayden KA, Serrett K. State-of-theevidence reviews: advantages and challenges of including grey literature. Worldviews Evid Based Nurs. 2006;3:55-61.

29. Singh S, Bajorek B. Defining, "elderly" in clinical practice guidelines for pharmacotherapy. Pharm Pract (Granada). 2014;12(4):489.

30. Shenkin SD, Harrison JK, Wilkinson T, Dodds RM, Ioannidis JPA. Systematic reviews: guidance relevant for studies of older people. Age Ageing. 2017;46:722-8.

31. World Health Organization (WHO). International drug monitoring: the role of national centres. Report of a WHO meeting. World Health Organ Tech Rep Ser. 1972;498:1-25.

32. Bates D, Cullen D, Laird N, et al. Incidence of adverse drug events and potential adverse drug events: implications for prevention. ADE Prevention Study Group. JAMA. 1995;274:29-34.

33. National Coordinating Council for Medication Error Reporting and Prevention. Questions about NCC MERP and medication errors. 2015. https://www.nccmerp.org/sites/default/files/nccme rp_fact_sheet_2015-02-v91.pdf. Accessed 26 Jan 2020.

34. National Coordinating Council for Medication Error Reporting and Prevention. About medication errors: what is a medication error. 2015. https://www.nccmerp.org/about-medication-error s. Accessed 26 Jan 2020.

35. Pippins JR, Gandhi TK, Hamann C, Ndumele CD, Labonville SA, Diedrichsen EK, et al. Classifying and predicting errors of inpatient medication reconciliation. J Gen Intern Med. 2008;23:1414-22. 
36. Mueller S, Sponsler K, Kripalani S, et al. Hospital-based medication reconciliation practices: a systematic review. Arch Intern Med. 2012;172:1057-69.

37. Thomson R, Pryce A. Chapter 4: patient safety-epidemiological considerations. In: Hurwitz B, Sheikh A, editors. Health care errors and patient safety. Oxford: Blackwell; 2009. p. 207-23.

38. Mateen FJ, Oh J, Tergas AI, Bhayani NH, Kamdar BB. Titles versus titles and abstracts for initial screening of articles for systematic reviews. Clin Epidemiol. 2013;5:89-95.

39. Jackson JL, Kuriyama A, Anton A, Choi A, Fournier J-P, Geier A-K, et al. The accuracy of Google Translate for abstracting data from non-English-language trials for systematic reviews. Ann Intern Med. 2019;171:2019-21.

40. Balk E, Chung M, Chen M. Assessing the accuracy of Google Translate to allow data extraction from trials published in non-English languages. Rockville (MD): Agency for Healthcare Research and Quality (US); 2013 Jan. Report No.: 12(13)-EHC145-EF. AHRQ Methods for Effective Health Care.

41. Higgins J, O'Connor D, Green S, editors. Cochrane handbook for systematic reviews of interventions. Chichester: Wiley; 2011.

42. Lisby M, Nielsen L, Brock B, Mainz J. How are medication errors defined: a systematic literature review of definitions and characteristics. Int J Qual Health Care. 2010;22:507-18.

43. Allan E, Barker K. Fundamentals of medication error in research. Am J Hosp Pharm. 1990;47:555-71.

44. Alsulami Z, Conroy S, Choonara I. Medication errors in the Middle East countries: a systematic review of the literature. Eur J Clin Pharmacol. 2013;69:995-1008.

45. Alshehri GH, Keers RN, Ashcroft DM. Frequency and nature of medication errors and adverse drug events in mental health hospitals: a systematic review. Drug Saf. 2017;40:871-86.

46. Ghaleb M, Barber N, Franklin B, et al. Systematic review of medication errors in pediatric patients. Ann Pharmacother. 2006;40:1766-76.

47. McLeod M, Barber N, Franklin B. Methodological variations and their effects on reported medication administration error rates. BMJ Qual Saf. 2013;27:278-89.

48. Crotty M, Rowett D, Spurling L, Giles LC, Phillips PA. Does the addition of a pharmacist transition coordinator improve evidence-based medication management and health outcomes in older adults moving from the hospital to a long-term care facility? Results of a randomized, controlled trial. Am J Geriatr Pharmacother. 2004;2:257-64.

49. Duggan C, Bates I, Hough J. Discrepancies in prescribing: where do they occure? Pharm J. 1996;265:65-7.

50. Duggan C, Feldman R, Hough J, Bates I. Reducing adverse prescribing discrepancies following hospital discharge. Int J Pharm Pract. 1998;6:77-82.

51. Eichenberger PM, Lampert ML, Kahmann IV, Van Mil JWF, Hersberger KE. Classification of drug-related problems with new prescriptions using a modified PCNE classification system. Pharm World Sci. 2010;32:362-72.

52. Fanizza F, Ruisinger J, Prohaska E, et al. Integrating in health information exchange into a community pharmacy transitions of care service. J Am Pharm Assoc. 2018;58:442-9.

53. Flanagan PS, Pawluk S, Bains S. Opportunities for medicationrelated support after discharge from hospital. Can Pharm J. 2010;143:170-5.

54. Forster AJ, Murff HJ, Peterson JF, Gandhi TK, Bates DW. Adverse drug events occurring following hospital discharge. J Gen Intern Med. 2005;20:317-23.

55. Gray S, Mahoney J, Blough D. Adverse drug events in elderly patients receiving home health services following hospital discharge. Ann Pharmacother. 1999;33:1147-53.
56. Hawes E, Pinelli N, Sanders K, Lipshutz A, Tong G, Sievers L, et al. Post-hospital discharge care: a retrospective cohort study exploring the value of pharmacist-enhanced care and describing medication-related problems. N C Med J. 2018;79:4-13.

57. Heyworth L, Paquin AM, Clark J, Kamenker V, Stewart M, Martin T, et al. Engaging patients in medication reconciliation via a patient portal following hospital discharge. J Am Med Inform Assoc. 2014;21:157-62.

58. Ahmad A, Mast MR, Nijpels G, Elders PJ, Dekker JM, Hugtenburg JG. Identification of drug-related problems of elderly patients discharged from hospital. Patient Prefer Adher. 2014;8:155-165.

59. Hockly M, Williams S, Allen M. Transfer of care: a randomised control trial investigating the effect of sending the details of patients' discharge medication to their community pharmacist on discharge from hospital. Int J Pharm Pract. 2018;26:174-82.

60. Holdhus H, Bøvre K, Mathiesen L, Bjelke B, Bjerknes K. Limited effect of structured medication report as the only intervention at discharge from hospital. Eur J Hosp Pharm. 2019;26:101-5.

61. Kanaan AO, Donovan JL, Duchin NP, Field TS, Tjia J, Cutrona SL, et al. Adverse drug events after hospital discharge in older adults: types, severity, and involvement of beers criteria medications. J Am Geriatr Soc. 2013;61:1894-9.

62. Letrilliart L, Hanslik T, Biour M. Postdischarge adverse drug reactions in primary care originating from hospital care in France. Drug Saf. 2001;24:781-93.

63. MacAulay S, Saulnier L, Gould O. Provision of clinical pharmacy services in the home to patients recently discharged from hospital: a pilot project. Can J Hosp Pharm. 2008;61:103-13.

64. Marusic S, Sicaja M, Neto P, et al. Adverse drug reactions in elderly patients following discharge from an internal medicine clinic. Int J Clin Pharmacol Ther. 2014;52:906-13.

65. Mesteig M, Helbostad JL, Sletvold O, Røsstad T, Saltvedt I. Unwanted incidents during transition of geriatric patients from hospital to home: a prospective observational study. BMC Health Serv Res. 2010;10:1-9.

66. Midlöv P, Bahrani L, Seyfali M, Höglund P, Rickhag E, Eriksson $\mathrm{T}$. The effect of medication reconciliation in elderly patients at hospital discharge. Int J Clin Pharm. 2012;34:113-9.

67. Ibrahim OHM. Impact of clinical pharmacist intervention on decreasing incidence of preventable adverse drug events after hospital discharge. Adv Pharmacoepidemiol Drug Saf. 2012;01:2-5.

68. Nagaraju K, Manasa S, Manjunath R. Pharmacovigilance study in geriatric population. Asian J Pharm Clin Res. 2015;8:395-9.

69. Al-Ghamdi SA, Mahmoud MA, Alammari MA, Al Bekairy AM, Alwhaibi M, Mayet AY, et al. The outcome of pharmacist counseling at the time of hospital discharge: an observational nonrandomized study. Ann Saudi Med. 2012;32:492-7.

70. Osorio SN, Abramson E, Pfoh ER, Edwards A, Schottel H, Kaushal R. Risk factors for unexplained medication discrepancies during transitions in care. Fam Med. 2014;46:587-96.

71. Paulino EI, Bouvy ML, Gastelurrutia MA, Guerreiro M, Buurma H, ESCP-SIR Rejkjavik Community Pharmacy Research Group. Drug related problems identified by European community pharmacists in patients discharged from hospital. Pharm World Sci. 2004;26:353-60.

72. Riordan CO, Delaney T, Grimes T. Exploring discharge prescribing errors and their propagation post-discharge: an observational study. Int J Clin Pharm. 2016;38:1172-81.

73. Salameh LK, Abu Farha RK, Abu Hammour KM, Basheti IA. Impact of pharmacist's directed medication reconciliation on reducing medication discrepancies during transition of care in hospital setting. J Pharm Health Serv Res. 2019;10:149-56. 
74. Schnipper J, Kirwin J, Cotugno M, Wahlstrom S, Brown B, Tarvin E, et al. Role of pharmacist counseling in preventing adverse drug events after hospitalization. Arch Intern Med. 2006;166:565-71.

75. Solanki R, Mondal N, Mahalakshmy T, Bhat V. Medication errors by caregivers at home in neonates discharged from the neonatal intensive care unit. Arch Dis Child. 2017;102:651-4.

76. Tetuan C, Guthrie K, Stoner S, et al. Impact of community pharmacist-performed post-discharge medication reviews in transitions of care. J Am Pharm Assoc (2003). 2018;58(6):659-66.

77. Tong E, Choo S, Ooi S-C, Newnham H. Improving the transition of elderly patients with multiple comorbidities into the community: impact of a pharmacist in a general medicine outpatient follow-up clinic. J Pharm Pract Res. 2015;45:117-21.

78. Tsilimingras D, Schnipper J, Duke A, Agens J, Quintero S, Bellamy G, et al. Post-discharge adverse events among urban and rural patients of an urban community hospital: a prospective cohort study. J Gen Intern Med. 2015;30:1164-71.

79. Westberg SM, Derr SK, Weinhandl ED, Adam TJ, Brummel AR, Lahti J, et al. Drug therapy problems identified by pharmacists through comprehensive medication management following hospital discharge. J Pharm Technol. 2017;33:96-107.

80. Al-Hashar A, Al-Zakwani I, Eriksson T, Sarakbi A, Al-Zadjali B, Al Mubaihsi S, et al. Impact of medication reconciliation and review and counselling, on adverse drug events and healthcare resource use. Int J Clin Pharm. 2018;40:1154-64.

81. Willoch K, Blix HS, Pedersen-Bjergaard AM, Eek AK, Reikvam A. Handling drug-related problems in rehabilitation patients: a randomized study. Int J Clin Pharm. 2012;34:382-8.

82. Armor BL, Wight AJ, Carter SM. Evaluation of adverse drug events and medication discrepancies in transitions of care between hospital discharge and primary care follow-up. J Pharm Pract. 2016;29:132-7.

83. Bergkvist A, Midlöv P, Höglund P, Larsson L, Bondesson Å, Eriksson T. Improved quality in the hospital discharge summary reduces medication errors-LIMM: Landskrona Integrated Medicines Management. Eur J Clin Pharmacol. 2009;65:1037-46.

84. Bonaudo M, Martorana M, Dimonte V, D'Alfonso A, Fornero G, Politano G, et al. Medication discrepancies across multiple care transitions: a retrospective longitudinal cohort study in Italy. PLoS One. 2018;13:1-13.

85. Braund R, Coulter CV, Bodington AJ, Giles LM, Greig AM, Heaslip LJ, et al. Drug related problems identified by community pharmacists on hospital discharge prescriptions in New Zealand. Int J Clin Pharm. 2014;36:498-502.

86. Buajordet I, Wesenberg F, Bros O. Adverse drug events in children during hospitalization and after discharge in a Norwegian University Hospital. Acta Paediatr. 2002;91:88-94.

87. Alldred D, Standage P, Zermansky A. Medication discrepancies and errors postdischarge from hospital: a pilot evaluation. Int $\mathrm{J}$ Pharm Pract. 2010;18:22.

88. Wilting I, Maanen ACD-V, Jansen PAF, Van Marum RJ, Egberts ACG. The effect of a multicomponent transitional pharmaceutical care intervention on the incidence and nature of unintentional medication discrepancies in geriatric patients after hospital discharge. Eur Geriatr Med. 2012;3:S118.

89. Sittambalam C, Thom C, Tran M, et al. Medication errors: improving quality of care and decreasing mistakes. American Geriatric Society, Special Issue 2015. Annual Scientific Meeting Abstract Book, 2015. p. 1-320.

90. Tantipinichwong N, Azizian K, Halbert S, et al. Impact on 30-day hospital readmissions of post-discharge medication reconciliation in a Medicare advantage patient population. J Am Geriatr Soc. 2017;65:16-7.
91. Wijekoon CN, Shanika LGT, Jayamanne S, Coombes J, Dawson A. Adverse drug reactions in a cohort of Sri Lankan patients with non-communicable chronic diseases. Clin Ther. 2017;39:e80.

92. Cameron K, Siu V, Hamandi B, Al E. Post-hospital discharge: medication discrepancies and drug therapy problems in primary care. Can J Hosp Pharm. 2010;63:72-3.

93. Claeys C, Senterre C, Neve J, Tulkens PM, Debusschere P, Spinewine A. Effect of a clinical pharmacist intervention on unintentional medication discrepancies after discharge: a prospective cohort study. Int J Clin Pharm. 2013;35:1286-7.

94. Donovan J, Kanaan A, Tija J, Al E. Identification of adverse drug events post-hospital discharge in a geriatric population. Pharmacotherapy. 2012;32:E255.

95. Huynh C, Jani Y, Wong ICK, Ghaleb M, Lo A, Crook J, Tandle $\mathrm{V}$, Tomlin S. Clinical significance of medication discrepancies in children post hospital discharge across five hospitals in England. Int J Pharm Pract. 2013;21(Suppl. S2):10-11.

96. Leland J, Cariaga J, Davis D, Al E. Home based transitional care. J Am Geriatr Soc. 2012;60:S212-3.

97. Mohammad R, Kim J, Donihi A, Coley K. Impact of hospitalbased pharmacist advocates in care transitions: identification and description of medication related interventions after patient discharge from hospital to home. Pharmacotherapy. 2011;31:338e.

98. Patel K, Wright DJ, Desborough J. Effectiveness of electronic discharge and handover system at Basildon and Thurrock University Hospitals NHS Foundation Trust: a service evaluation. Int J Pharm Pract. 2011;19:34.

99. Pourrat X, Roux C, Bouzige B, Garnier V, Develay A, Fraysse $\mathrm{M}$, et al. Impact of drug reconciliation at discharge and communication between hospital and community pharmacists on drugrelated problems: a randomized controlled trial. Int J Clin Pharm. 2017;39:212-3.

100. Drenth-van C, Wilting I, Jansen P, van Marum R, Egberts T. Effect of a discharge medication intervention on the incidence and nature of medication discrepancies in older adults. J Am Geriatr Soc. 2013;61:456-8.

101. Dean B, Barber N, Schachter M. What is a prescribing error? Qual Saf Health Care. 2000;9:232-7.

102. Committee JF. British National Formulary London. https://www. medicinescomplete.com. Accessed 27 May 2019.

103. Grissinger M. Measuring up to medication safety in hospitals. Pharm Ther. 2009;34:10-50.

104. Tam V, Knowles S, Cornish P, et al. Frequency, type and clinical importance of medication history errors at admission to hospital: a systematic review. Can Med Assoc J. 2005;173:510-5.

105. De Vries E, Ramrattan M, Smorenburg S, Gouma D, Boermeester $M$. The incidence and nature of in-hospital adverse events: a systematic review. Qual Saf Health Care. 2008;17:216-23.

106. Thomsen LA, Winterstein AG, Søndergaard B, Haugbølle LS, Melander A. Systematic review of the incidence and characteristics of preventable adverse drug events in ambulatory care. Ambul Care. 2007;41:1411-26.

107. NICE. NICE Guideline: medicines optimisation: the safe and effectiv effective use of medicines to enable the best possible outcomes. London: NICE; 2017.

108. Scottish Intercollegiate Guidelines Network (SIGN). SIGN guideline 128: the SIGN discharge document. Healthc Improv Scotl. 2012;18. https://www.sign.ac.uk/assets/sign128.pdf. Access 26 Feb 2020.

109. World Health Organization. Transitions of care: technical series on safer primary care. 2016. https://apps.who.int/iris/bitstream/ handle/10665/252272/9789241511599-eng.pdf;jsessionid $=$ F02F4867BC0581E4B21DE72B23FC0994 sequence $=1$. Accessed 21 Feb 2020.

110. Health Quality Ontario. Quality standards. Transitions between hospital and home: care for people of all ages. 2019. https:// 
www.hqontario.ca/Portals/0/documents/evidence/quality-stand ards/qs-transitions-between-hospital-and-home-quality-stand ard-en.pdf. Accessed 21 Feb 2020.

111. Mangoni AA, Jackson SHD. Age-related changes in pharmacokinetics and pharmacodynamics: basic principles and practical applications. Br J Clin Pharmacol. 2003;57:6-14.

112. Brahma D, Wahlang J, Marak M, Sangma M. Adverse drug reactions in the elderly. J Pharmacol Pharmacother. 2013;4:91-4.

113. Mallet L, Spinewine A, Huang A. The challenge of managing drug interactions in elderly people. Lancet. 2007;370:250-1.

114. Nobili A, Garattini S, Mannucci PM. Multiple diseases and polypharmacy in the elderly: challenges for the internist of the third millennium. J Comorbidity. 2011;1:28-44.

115. Simonson W, Feinberg JL. Medication-related problems in the elderly. Drugs Aging. 2005;22:559-69.

116. World Health Organization. Medication safety in transitions of care. 2019. https://www.who.int/patientsafety/medication-safet y/technical-reports/en/. Accessed 21 Feb 2020.

117. Gattari TB, Krieger LN, Hu HM, Mychaliska KP. Medication discrepancies at pediatric hospital discharge. Hosp Pediatr. 2015;5:439-45.

118. Jones CD, Wald HL, Boxer RS, Masoudi FA, Burke RE, Capp R, et al. Characteristics associated with home health care referrals at hospital discharge: results from the 2012 national inpatient sample. Health Serv Res. 2017;52:879-94.

119. Jones CD, Jones J, Richard A, Bowles K, Lahoff D, Boxer RS, et al. "Connecting the dots": a qualitative study of home health nurse perspectives on coordinating care for recently discharged patients. J Gen Intern Med. 2017;32:1114-21.

120. Patterson ME, Foust JB, Bollinger S, Coleman C, Nguyen D. Inter-facility communication barriers delay resolving medication discrepancies during transitions of care. Res Soc Adm Pharm. 2019;15:366-9.

121. United Nation. Country classification. World Economic Situation and Prospects; 2014. https://www.un.org/en/development/desa/ policy/wesp/wesp_current/2014wesp_country_classification.pdf. Accessed 26 Feb 2020

122. Arya N, Gibson C, Ponka D, Haq C, Hansel S, Dahlman B, et al. Family medicine around the world: overview by region. Can Fam Physician. 2017;63:436-41.

123. Panagioti M, Khan K, Keers RN, Abuzour A, Phipps D, Kontopantelis E, et al. Prevalence, severity, and nature of preventable patient harm across medical care settings: systematic review and meta-analysis. BMJ. 2019;17(366):14185. https://doi. org/10.1136/bmj.14185.

124. Beijer HJM, De Blaey CJ. Hospitalisations caused by adverse drug reactions (ADR): a meta-analysis of observational studies. Pharm World Sci. 2002;24:46-54.

125. Howard RL, Avery AJ, Slavenburg S, Royal S, Pipe G, Lucassen $\mathrm{P}$, et al. Which drugs cause preventable admissions to hospital? A systematic review. Br J Clin Pharmacol. 2006;63:136-47.

126. Avery AJ, Rodgers S, Cantrill JA, Armstrong S, Cresswell K, Eden M, et al. A pharmacist-led information technology intervention for medication errors (PINCER): a multicentre, cluster randomised, controlled trial and cost-effectiveness analysis. Lancet. 2012;379:1310-9.

127. Parekh N, Ali K, Davies JG, Stevenson JM, Banya W, Nyangoma $\mathrm{S}$, et al. Medication-related harm in older adults following hospital discharge: development and validation of a prediction tool. BMJ Qual Saf. 2020;29:142-53.

128. Avery AJ, Dex GM, Mulvaney C, Serumaga B, Spencer R, Lester HE, et al. Development of prescribing-safety indicators for GPs using the RAND appropriateness method. Br J Gen Pract. 2011;61:526-36.
129. Spencer R, Bell B, Avery AJ, Gookey G, Campbell SM. Identification of an updated set of prescribing-safety indicators for GPs. Br J Gen Pract. 2014;64:181-90.

130. Wessell A, Ornstein S, Jenkins R, Nemeth L, Litvin C, Nietert P. Medication safety in primary care practice: results from a PPRNet quality improvement intervention. Am J Med Qual. 2013;28:16-24.

131. Elliott RA, Boyd MJ, Tanajewski L, Barber N, Gkountouras G, Avery AJ, et al. "New Medicine Service": supporting adherence in people starting a new medication for a long-term condition: 26-week follow-up of a pragmatic randomised controlled trial. BMJ Qual Saf. 2019. https://doi.org/10.1136/bmjqs-2018-009177 (Epub ahead of print).

132. Lewis P, Dornan T, Taylor D, et al. Prevalence, incidence and nature of prescribing errors in hospital inpatients: a systematic review. Drug Saf. 2009;32:379-89.

133. Keers R, Williams S, Cooke J, Ashcroft D. Causes of medication administration errors in hospitals: a systematic review of quantitative and qualitative evidence. Drug Saf. 2013;36:1045-67.

134. Alhawassi T, Krass I, Bajorek B, Pont L. A systematic review of the prevalence and risk factors for adverse drug reactions in the elderly in the acute care setting. Clin Interv Aging. 2014;9:2079-86.

135. Cardoso T, Almeida M, Friedman ND, Aragão I, Costa-Pereira A, Sarmento AE, et al. Classification of healthcare-associated infection: a systematic review 10 years after the first proposal. BMC Med. 2014;12:1-13.

136. Chin D, Bang H, Manickam R, Romano P. Rethinking 30-day hospital readmissions: shorter intervals might be better indicators of quality of care. Health Aff (Millwood). 2016;35:1867-75.

137. Coleman EA, Min SJ, Chomiak A, Kramer AM. Posthospital care transitions: patterns, complications, and risk identification. Health Serv Res. 2004;39:1449-65.

138. Hasson F, Keeney S, McKenna H. Research guidelines for the Delphi survey technique. J Adv Nurs. 2000;32:1008-15.

139. Sanderson S, Tatt I, Higgins J. Tools for assessing quality and susceptibility to bias in observational studies in epidemiology: a systematic review and annotated bibliography. Int J Epidemiol. 2007;36:666-76.

140. Motamedi SM, Posadas-Calleja J, Straus S, Bates DW, Lorenzetti DL, Baylis B, et al. The efficacy of computer-enabled discharge communication interventions: a systematic review. BMJ Qual Saf. 2011;20:403-15.

141. Kwan J, Lo L, Sampson M, et al. Annals of internal medicine supplement medication reconciliation during transitions of care as a patient safety strategy. Ann Intern Med. 2013;158:397-403.

142. Nazar H, Nazar Z, Portlock J, Todd A, Slight SP. A systematic review of the role of community pharmacies in improving the transition from secondary to primary care. Br J Clin Pharmacol. 2015;80:936-48.

143. Mills PR, Weidmann AE, Stewart D. Hospital discharge information communication and prescribing errors: a narrative literature overview. Eur J Hosp Pharm. 2016;23:3-10.

144. Redmond P, Tc G, Mcdonnell R, Boland F, Hughes C, Fahey T. Impact of medication reconciliation for improving transitions of care. Cochrane Database Syst Rev. 2018;23(8):CD010791.

145. Mcnab D, Bowie P, Ross A, Macwalter G, Ryan M, Morrison J. Systematic review and meta-analysis of the effectiveness of pharmacist-led medication reconciliation in the community after hospital discharge. BMJ Open. 2018;27:308-20.

146. Bethishou L, Herzik K, Fang N, Abdo C, Tomaszewski D. The impact of the pharmacist on continuity of care during transitions of care: a systematic review. J Am Pharm Assoc. 2020;60(163-77):e2.

147. Anderson JE, Kodate N, Walters R, Dodds A. Can incident reporting improve safety? Healthcare practitioners' views of 
the effectiveness of incident reporting. Int J Qual Health Care. 2013;25:141-50.

148. Stavropoulou C, Doherty C, Tosey P. How effective are incidentreporting systems for improving patient safety? A systematic literature review. Milbank Q. 2015;93:826-66.

149. Williams H, Edwards A, Hibbert P, Rees P, Evans HP, Panesar $\mathrm{S}$, et al. Harms from discharge to primary care: mixed methods analysis of incident reports. Br J Gen Pract. 2015;65:e829-37.

150. Parekh N, Gahagan B, Ward L, et al. 'They must help if the doctor gives them to you': a qualitative study of the older person's lived experience of medication-related problems. Age Ageing. 2019;48:147-51.

151. Foulon V, Wuyts J, Desplenter F, Spinewine A, Lacour V, Paulus $\mathrm{D}$, et al. Problems in continuity of medication management upon transition between primary and secondary care: patients' and professionals' experiences. Acta Clin Belg. 2019;74:263-71.

152. Mackridge AJ, Rodgers R, Lee D, Morecroft CW, Krska J. Crosssectional survey of patients' need for information and support with medicines after discharge from hospital. Int J Pharm Pract. 2018;26:433-41.

153. Fylan B, Tranmer M, Armitage G, Blenkinsopp A. Cardiology patients' medicines management networks after hospital discharge: a mixed methods analysis of a complex adaptive system. Res Soc Adm Pharm. 2019;15:505-13.

154. Bagge M, Norris P, Heydon S, Tordoff J. Older people's experiences of medicine changes on leaving hospital. Res Soc Adm Pharm. 2014;10:791-800.

155. Daliri S, Bekker CL, Buurman BM, Scholte op Reimer WJM, van den Bemt BJF, Karapinar-Çarkit F. Barriers and facilitators with medication use during the transition from hospital to home: a qualitative study among patients. BMC Health Serv Res. 2019;19:204

156. Mullan RJ, Flynn DN, Carlberg B, Tleyjeh IM, Kamath CC, Labella ML, et al. Systematic reviewers commonly contact study authors but do so with limited rigor. J Clin Epidemiol. 2009;62:138-42.

157. Waffenschmidt S, Knelangen M, Sieben W, Bühn S, Pieper D. Single screening versus conventional double screening for study selection in systematic reviews: a methodological systematic review. BMC Med Res Methodol. 2019;19:1-9.

\section{Affiliations}

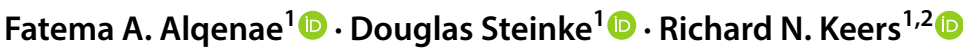

1 Division of Pharmacy and Optometry, School of Health Sciences, Centre for Pharmacoepidemiology and Drug Safety, University of Manchester, Oxford Road,

Manchester M13 9PT, UK
2 Pharmacy Department, Greater Manchester Mental Health NHS Foundation Trust, Manchester, UK 